\title{
REPORT ON PROFICIENCY TESTING
}

\section{Report on the External Quality Assessment Scheme for Hemoglobin A1c in Korea (2016-2017)}

Sun Hee Jun, Kyunghoon Lee, and Junghan Song Department of Laboratory Medicine, Seoul National University Bundang Hospital, Seoul National University College of Medicine, Seongnam, Korea

Corresponding author: Junghan Song

Department of Laboratory Medicine, Seoul National University Bundang Hospital, Seoul National University College of Medicine, 82 Gumiro 173beon-gil, Bundang-gu, Seongnam 13620, Korea Tel: $+82-31-787-7691$

Fax: $+82-31-787-4015$

E-mail: songjhcp@snu.ac.kr
As part of the clinical chemistry programs of the Korean Association of External Quality Assessment Service, we organized trials to conduct external quality assessment of hemoglobin A1c (HbAlc) in 2016 and 2017. We delivered three commutable whole blood specimens for each trial. The overall response rates were $96.4 \%$ in 2016 and $98.4 \%$ and $99.6 \%$ in the first and second trials in 2017, respectively. Two types of reports were generated: a common report including the mean, standard deviation, coefficient of variation, median, minimum value, and maximum value according to manufacturer and instrument, as well as a summary report of the results from each participating laboratory, including a histogram for each specimen, Levey-Jennings chart for serial percent deviations, and table showing the target value, upper and lower limits, percent deviation, and grade. From 2016, the acceptance criterion was changed from $\pm 8.0 \%$ to $\pm 6.7 \%$. The overall acceptable rates for the survey were $91.5 \%, 91.4 \%, 94.9 \%$, and $89.0 \%$ for the first trial in 2016 through the second trial in 2017, respectively. The requisite continual improvement in the quality of $\mathrm{HbAlc}$ testing can be achieved through participation in similar accuracy-based proficiency testing programs.

(J Lab Med Qual Assur 2018;40:178-181)

Key Words: Korean Association of External Quality Assessment Service, Laboratory proficiency testing, Hemoglobin Alc
서론

대한임상검사정도관리협회 hemoglobin $\mathrm{Alc}(\mathrm{HbA} 1 \mathrm{c})$ 검 사는 생화학분과가 담당하던 신빙도조사사업을 2009년부터 임상화학분과가 시행을 담당하였고 2016년부터 새로운 방 식의 차세대 신빙도조사사업이 프로그램 단위로 바뀜에 따 라 임상화학분과에서 단일 프로그램으로 변경되어 시행되고 있다[1,2]. HbA1c 신빙도조사사업은 2009년부터 기질효과 (matrix effect)가 없는 commutable한 정도관리물질을 제조 하여 사용하였고 연 2회 시행하였다. 저자들은 2016년과 2017 년 실시되었던 정확도기반 $\mathrm{HbA1c}$ 에 대한 신빙도조사사업 결 과를 분석하여 보고하고자 한다.

\section{재료 및 방법}

1. 대상

대한임상검사정도관리협회에 정확도 $\mathrm{HbA1c}$ 프로그램을 신 청한 기관인 2016년 1회차 394기관, 2회차 394기관, 2017년 1 회차 425 기관, 2 회차 470 기관을 대상으로 하였다.

\section{2. 재료}

2016년과 2017년의 $\mathrm{HbA1c}$ 신빙도조사사업에 사용 했던 검체는 정상인 1 명과 당뇨병을 지닌 환자 2 명에게 서 전혈을 기증받아 사용하였다. 이때 전혈은 항응고제로 ethylenediaminetetraacetic acid가 들어 있는 혈액백을 사 용하였고 기증받은 전혈은 모두 human immunodeficiency virus 항체와 B형간염항원이 음성임을 확인하였다. 세 명의 


\section{Journal of LABORATORY MEDICINE and QUALITY ASSURANCE}

Sun Hee Jun et al • Report on the EQAS for HbA1c in Korea (2016-2017)

환자에게서 기증받은 전혈은 비예기항체 등 용혈이 발생될 수 있는 요인을 줄이기 위하여 기증받은 전혈을 섞지 않고 그대로 $500 \mu \mathrm{L}$ 씩 검체용기에 분주한 후 냉장상태로 대한임상검사정 도관리협회로 보냈으며, 협회에서는 당일 오후에 바로 택배를 이용하여 각 기관으로 발송하였다.

참값(target value)은 제조한 검체를 동시에 International Federation of Clinical Chemistry Network Laboratory 인 질병관리본부 국가진단의학검사 표준검사실에 보내어 받

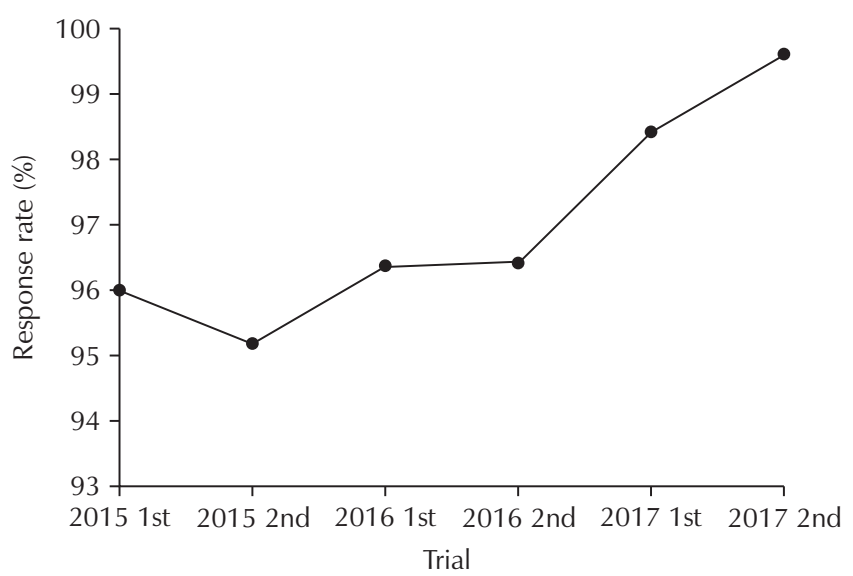

Fig. 1. Recent response rates of accuracy-based hemoglobin A1c proficiency testing (2015-2017).
은 참값으로 정하였다. 각 검체마다 판정기준은 총 오차(total error) $6.7 \%$ 를 참고하여[3], target value $\pm 6.7 \%$ 값을 각각 lower limit, upper limit으로 제시하고 lower limit과 upper limit 범위 안에 들어오는 결과값을 'acceptable'로 판정하였 다. 결과값과 target value의 차이는 percent deviation을 구 하여 제시하였다.

종합보고서의 통계분석은 전체기관, 제조회사별, 측정기 기별로 시행하였다. 참여기관 수가 10 개 이상인 경우 평균 (mean), 표준편차(standard deviation), 변이계수(coefficient of variation)를 계산하여 제시하였다. 참가기관 수에 따라서 보고가 가능한 중앙값(median), 최소값(min), 최대값(max) 을 제시하였다.

\section{결과 및 고찰}

\section{1. 참여기관 및 회신율}

2016년도 참여한 기관은 1,2 회차 모두 394 기관 중 380 기관 이 회신하여 회신율은 $96.4 \%$ 였다. 2017 년도 참여기관은 1 회 차는 425 기관 중 418 기관이, 2 회차는 470 기관 중 468 기관이 회신하여 회신율은 각각 $98.4 \%, 99.6 \%$ 였다(Fig. 1).

\section{2. 검사방법 및 검사장비}

2016년도 1회차 경우 가장 많이 사용하고 있는 방법은

Table 1. Distribution of manufacturers and methods in accuracy-based hemoglobin A1c proficiency testing

\begin{tabular}{|c|c|c|c|c|c|}
\hline \multirow{2}{*}{ Manufacturer } & \multirow{2}{*}{ Method } & \multicolumn{2}{|c|}{2016} & \multicolumn{2}{|c|}{2017} \\
\hline & & 1st trial & 2nd trial & 1st trial & 2nd trial \\
\hline Alere Inc. & Boronate affinity & 6 & 8 & 9 & 19 \\
\hline Bio-Rad & Ion exchange HPLC & 117 & 119 & 128 & 135 \\
\hline Boditech & Immunoassay & 2 & 1 & 1 & 3 \\
\hline Infopia & Boronate affinity & 4 & 4 & 3 & 12 \\
\hline Roche & Immunoassay & 39 & 38 & 39 & 39 \\
\hline Siemens Healthcare Diagnostics Inc. & Immunoassay & 7 & 7 & 6 & 7 \\
\hline Tokyo Boeki Medisys Inc. & - & 0 & 1 & 1 & 1 \\
\hline SD Biosensor & Immunoassay & 0 & 0 & 2 & 6 \\
\hline i-SENS & Enzymatic assay & 0 & 0 & 2 & 4 \\
\hline Others & - & 27 & 18 & 18 & 16 \\
\hline
\end{tabular}

Abbreviation: HPLC, high performance liquid chromatography. 
Journal of LABORATORY MEDICINE and QUALITY ASSURANCE

Sun Hee Jun et al • Report on the EQAS for HbA1c in Korea (2016-2017)

Table 2. Results of accuracy-based hemoglobin A1c proficiency testing in 2016

\begin{tabular}{|c|c|c|c|c|c|c|}
\hline \multirow{2}{*}{ Specimen } & \multicolumn{3}{|c|}{ 1st trial } & \multicolumn{3}{|c|}{ 2nd trial } \\
\hline & CAH-16-01 & CAH-16-02 & CAH-16-03 & CAH-16-04 & CAH-16-05 & CAH-16-06 \\
\hline Target value (\% NGSP) & 10.00 & 6.82 & 5.33 & 7.90 & 7.07 & 5.11 \\
\hline \multicolumn{7}{|l|}{ Your grade } \\
\hline Acceptable & 334 & 353 & 356 & 358 & 352 & 332 \\
\hline Acceptance rate (\%) & 87.9 & 92.9 & 93.7 & 94.2 & 92.6 & 87.4 \\
\hline
\end{tabular}

Abbreviation: NGSP, National Glycohemoglobin Standardization Program

Table 3. Results of accuracy-based hemoglobin A1c proficiency testing in 2017

\begin{tabular}{|c|c|c|c|c|c|c|}
\hline \multirow{2}{*}{ Specimen } & \multicolumn{3}{|c|}{ 1st trial } & \multicolumn{3}{|c|}{ 2nd trial } \\
\hline & CAH-17-01 & CAH-17-02 & CAH-17-03 & CAH-17-04 & CAH-17-05 & CAH-17-06 \\
\hline Target value (\% NGSP) & 5.52 & 7.76 & 11.57 & 5.36 & 7.39 & 9.76 \\
\hline \multicolumn{7}{|l|}{ Your grade } \\
\hline Acceptable & 401 & 401 & 388 & 416 & 443 & 391 \\
\hline Acceptance rate (\%) & 95.9 & 95.9 & 92.8 & 88.9 & 94.7 & 83.5 \\
\hline
\end{tabular}

Abbreviation: NGSP, National Glycohemoglobin Standardization Program

ion exchange high performance liquid chromatography (HPLC) 방법으로 70\%를 차지하였으며, Tosoh, Bio-Rad, Arkray Inc. 제조회사의 기기들이 많이 사용되고 있었다 (Table 1). 그 다음으로는 immunoassay 방법으로 $17 \%$ 를 차 지하였으며, Roche, Siemens, Beckman Coulter 등의 시약 을 사용하고 있었다. 범용시약(Reagent for open systems) 의 경우 Sekisui HbA1c 11기관, Beckman Coulter HbA1c 8 기관, 아이비디랩 $\mathrm{HbA1c} 5$ 기관, 신화메디 2기관, others 1 기 관이 사용하고 있었다. 2017년도 2회차의 경우 가장 많이 사 용하고 있는 방법은 여전히 ion exchange HPLC 방법(68\%) 이었으며, 그 다음으로는 immunoassay 방법(15\%)이었다. Boronate affinity 방법(8\%)이 enzymatic assay 방법(3\%)보 다 3 배 정도 늘어서 세 번째로 많이 사용하는 방법이 되었다. Alere Inc.의 Afinion과 Infopia 이지에이원씨 제품을 사용하 는 기관 수의 증가가 boronate affinity 방법의 증가에 가장 큰 영향을 준 것으로 판단된다.

\section{3. 검체별 결과분석}

2016년 1회차 각 검체마다의 정답률(acceptance rate)을 보 면 $\mathrm{CAH}-16-01$ 검체는 $87.9 \%, \mathrm{CAH}-16-02$ 검체는 $92.6 \%$,
CAH-16-03 검체는 93.7\%이었다(Table 2). 2회차의 경우 는 $\mathrm{CAH}-16-04, \mathrm{CAH}-16-05, \mathrm{CAH}-16-06$ 검체번호 순서대 로 각각 $94.2 \%, 92.6 \%, 87.4 \%$ 였다. 2016년도부터는 기준 을 target value의 $6.7 \%$ 로 이전의 $8 \%$ 에서 보다 엄격하게 적 용하였으나, 각 회차마다 모든 검체에서 acceptable을 받은 기관 수의 퍼센트는 크게 감소하지 않았다. 하지만 target 값 이 10.00\% National Glycohemoglobin Standardization Program (NGSP)로 높거나 5.11\% NGSP로 낮은 경우에서 는 acceptance rate가 상대적으로 감소하는 것을 확인할 수 있 었다. $10.00 \% \mathrm{NGSP}$ 에서 unacceptable을 받은 기관은 범용 시약 19 기관, Roche 15 기관, others 8 기관 순이었으나, $5.11 \%$ NGSP에서 unacceptable을 받은 기관은 Bio-Rad 21기관, Roche 9 기관, 범용시약 6 기관 순이었다. 2017 년 1 회차 각 검 체마다의 정답률은 $95.9 \%, 95.9 \%, 92.8 \%$ 로 2016년보다 증 가한 소견을 보였지만, 2017 년 2회차의 정답률은 각각 $88.9 \%$, $94.7 \%, 83.5 \%$ 로 오히려 감소하였다(Table 3 ). 이러한 원인으 로는 우선 $\mathrm{CAH}-17-04$ 검체의 참값이 $5.36 \% \mathrm{NGSP}, \mathrm{CAH}-$ 17-06 검체의 참값이 9.76\% NGSP로 높은 값이어서 다른 회 차에 비해서 정답률이 감소한 것으로 생각이 된다. 또한 10 기관이 clerical error로 결과값을 잘못 입력한 것도 정답률 


\section{Journal of LABORATORY MEDICINE and QUALITY ASSURANCE}

Sun Hee Jun et al • Report on the EQAS for HbA1c in Korea (2016-2017)

이 낮은 원인 중 하나이며, 정부의 질가산율 발표이후 대한임 상검사정도관리협회 신빙도조사사업에 처음 참여하는 기관 이 증가한 것도 하나의 원인으로 생각된다. $5.36 \% \mathrm{NGSP}$ 에 서 unacceptable을 받은 기관은 Bio-Rad 31기관, others 5 기관, Arkray Inc. 4기관 순이었으며, $9.76 \% \mathrm{NGSP}$ 의 경우 Bio-Rad 17기관, Arkray Inc. 13기관, Infopia 10기관 순이 었다. 특히 Infopia의 경우 12 기관 중 10 기관이 unacceptable 을 받았으며, Trinity Biotech의 경우도 5 기관 중 4 개 기관이 unacceptable을 받았다.

\section{REFERENCES}

1. Jun SH, Song J, Song WH; Clinical Chemistry Subcommit- tee, Korean Association of External Quality Assessment Service. Annual report on the external quality assessment scheme for clinical chemistry in Korea (2015). J Lab Med Qual Assur 2016;38:111-9.

2. Lee YW, Jeon BR, Kim JG, Jun SH, Yun YM, Chun S, et al. Annual report on the external quality assessment scheme for routine clinical chemistry in Korea (2016). J Lab Med Qual Assur 2017;39:61-75.

3. Weykamp CW, Mosca A, Gillery P, Panteghini M. The analytical goals for hemoglobin A(1c) measurement in IFCC units and National Glycohemoglobin Standardization Program units are different. Clin Chem 2011;57: 1204-6. 